\title{
Implementation of Self Reporting Pharmacovigilance in Anti Tubercular Therapy Using Knowledge Based Approach
}

Sainul Abideen $\mathbf{P}^{1^{*}}$, Chandrasekaran $\mathrm{K}^{2}$, Uma Maheswaran ${ }^{2}$, Vijayakumar $\mathbf{A}^{2}$, Kalaiselvan V³ Pradeep Mishra $^{4}$, Moza Al Hail ${ }^{5}$, Abdul Rouf and Binny Thomas ${ }^{5}$

${ }^{1}$ Department of Clinical Pharmacology, Narayana Hrudayalaya Hospital, Jaipur, Rajastan, India

${ }^{2}$ Department of Pharmacy Practice, KMCH College of Pharmacy, Coimbatore, Tamil Nadu, India

${ }^{3}$ Indian Pharmacopoeia Commission, Sector 23, Raj Nagar, Ghaziabad, UP, India

${ }^{4}$ PMS Arts \& Communications, New Delhi, India

${ }^{5}$ Hamad Medical Corporation, Qatar

\begin{abstract}
Tuberculosis (TB) hampered with poor patient compliance and intolerance at least partially due to adverse drug reactions (ADRs). A prospective observational and interventional healthcare teamwork study was carried out to implement a self-reporting pharmacovigilance system in TB patients through a knowledge based approach in the Pulmonology department of Kovai Medical Center and Hospital (KMCH) at Coimbatore. A patient information pamphlet which was endorsed by the pulmonology associates was the core tool for this study. A well practiced and skilled clinical pharmacist educated the patients and enabled them to report the ADRs due to anti tubercular drugs through the emergency number given in the pamphlet. Totally 110 patients enrolled in the study. 43 (39\%) patients experienced 74 numbers of ADRs during the intensive phase therapy. Out of 110 patients, 101 were adhered to the intensive phase therapy. Of the 74 ADRs experienced to our study population, 24 ADRs were occurred in 18 patients which are needed to be self reported by the patient according to the study protocol. Among 24 ADRs which have to be self reported, $20(83.33 \%)$ ADRs were reported through 17 calls by 16 patients. The self-reporting pharmacovigilance for anti-tubercular therapy in pulmonology department of $\mathrm{KMCH}$, Coimbatore, were implemented and was certified by the pulmonology associates. Our study concludes that if a proper educational system is implemented, most of the patients were ready to report their ADR of any drug and thereby we can improve both patient adherence and reducing the severity of ADRs. It is suggested that the pharmacists should exhibit their vital role during TB therapy in TB centres, pulmonology departments and DOTS centres to guarantee a better patient care.
\end{abstract}

Keywords: Self reporting pharmacovigilance; Anti-TB drugs; Clinical pharmacist; ADR reporting system

\section{Introduction}

Tuberculosis (TB) is the most rampant communicable infectious disease on earth and remains out of control in many developing nations. Good patient adherence to the treatment regimens is the foundation stone to effective Anti Tubercular Therapy (ATT) [1]. Alas, non compliance is cited as the major problem to the control of tuberculosis at the level of public health and finally which escort to the drug resistance in case of TB [2-4].

ATT exhibits greater level of efficacy with a satisfactory degree of toxicity; however combination treatment may produce severe adverse events. Important adverse effects are hepatitis, joint pain, skin rash, gastro intestinal upset (nausea/vomiting/GI upset), hyperuricemia, constipation, peripheral neuropathy, and visual disturbances [5-14]. TB hampered with poor patient compliance and intolerance at least partially due to the ADRs. According to World Health Organization (WHO) and several other studies concluded that, the poor out-come was attributed to poor patient compliance, to primary multidrug resistance and to interruption partially due to ADR (WHO 1997) $[3,7,8,13,15-19]$ and the towering incidence of TB infection has caused a high occurrence of morbidity and mortality which is partly due to serious ADRs induced by Anti- TB drugs [12].

Patient's decisions to stop taking medications were influenced by a number of interacting factors $[17,19]$. The lack of knowledge about the treatment and ATT induced ADRs are the two major factors which leads to the patient's non-adherence to the TB therapy. A qualitative and quantitative study by Weiguo et al. [20] stated that almost 16 factors which leads to the non adherence for the TB treatment. Majority of them are due to the lack of knowledge about the importance of the completion of therapy. Out of these 16 factors $37.80 \%$ (which is the highest percentage) of patients were non adherent due to the severe ADRs [20]. Schaberg et al. [7] were also stated that $26 \%$ of TB patients in the study population were discontinued therapy due side effects.

The influence of side effects - real, anticipated or interpreted on compliance to treatment was mentioned in a number of studies. Some patients reported stopping medication due to adverse effects while others complained that they were not educated about side effects and what to do to counter them [17]. In-depth interviews among both TB patients and local doctors point out that ADR is a motive for treatment non-adherence. Worry of the risks of ADRs leads some TB patients to break off the treatment [20] "... I don't want to take these pills, because they make me sick, they hurt me..." (Female TB patient, Bolivia) is an example for the above statement [17]. Local health workers often cannot find out this discontinuation of treatment due to the lack of an ADR surveillance system under the current DOTS program [20]. Counselling

*Corresponding author: Sainul Abideen P, Department of Clinical Pharmacology, Narayana Hrudayalaya Hospital, Jaipur, Rajastan, India, Tel: +91 9982510140 E-mail: iamaabid@gmail.com

Received December 10, 2012; Accepted December 27, 2012; Published December 29, 2012

Citation: Abideen PS, Chandrasekaran K, Uma Maheswaran, Vijayakumar A Kalaiselvan V, et al. (2013) Implementation of Self Reporting Pharmacovigilance in Anti Tubercular Therapy Using Knowledge Based Approach. J Pharmacovigilance 1: 101. doi:10.4172/2329-6887.1000101

Copyright: @ 2013 Abideen PS, et al. This is an open-access article distributed under the terms of the Creative Commons Attribution License, which permits unrestricted use, distribution, and reproduction in any medium, provided the original author and source are credited. 
Citation: Abideen PS, Chandrasekaran K, Uma Maheswaran, Vijayakumar A, Kalaiselvan V, et al. (2013) Implementation of Self Reporting Pharmacovigilance in Anti Tubercular Therapy Using Knowledge Based Approach. J Pharmacovigilance 1: 101. doi:10.4172/2329-6887. 1000101

of patients for timely hindrance, revealing and management of ADRs was also highly suggestive [11]. Also it is already proved that patients were clearly willing to report symptoms which they believe to be due to a particular prescribed drug if they were informed about it. So it is fundamentally required a system for proper monitoring of ADRs due to anti tubercular drugs. Several studies were suggesting the significance of a new system for premature detection of ADR for a better patient care $[8,10,21]$.

This leads to taking a decision to do an intervention of a new health care teamwork approach with an intention to complete patient care during ATT with a special preference on ADR reporting system. The evidence of patient's definite role in ADR and their willingness to report the ADR [22-25] were planned to utilize in this study by expecting a good adherence. Here comes the importance of pharmaceutical care based approach to the TB patient. This study is one of the clinical pharmacy come health care team work oriented one, aiming for the best quality of life of tuberculosis patient during their therapy by implementing an educational approach to them regarding on both the therapy and how to counteract the possible ADRs during Anti Tubercular Therapy.

\section{Materials and Methods}

The present study is prospective observational and interventional study conducted in Department of pulmonology, of an 800 bedded super specialty hospital at Coimbatore, Tamilnadu, for a period of 8 months. Study was approved by the concerned authorities. Both the inpatients and outpatients who received the prescription of Anti Tubercular drugs aged between 16 to 75 years were included in the study. Even though we are given the education, patients who referred to their nearest clinic or physician for continuation the treatment after diagnosing from the present study site, were excluded from the study. Also patient who has MDR TB, patients with co-morbidity medical/ surgical condition and mentally retarded patients were excluded.

A patient information pamphlet named as "Things to be Noticed While Taking Medicines for Tuberculosis" (both in Tamil and English) which was evaluated and validated by the pulmonology physicians is the core tool for this study. This is particularly prepared for enabling and initiating the patient to report the ADR. The pamphlet provides the information's on TB, possible ADR during ATT and the emergency contact number of both the physician and pharmacist to report ADR by the patient itself once if they suspect the ADR. Adverse drug reactions which are illustrated in the patient information pamphlet were only considered to evaluate effectiveness of self reporting pharmacovigilance system. They include nausea/vomiting, joint pains, loss of appetite, weight loss, yellow colorations of eye and skin, vision problem, skin itch/rash and abdominal pain. ADR incidence during the time of hospital period was excluded from the self report. Calls received which are not related to ADR were also excluded from report.

\section{Educational module}

A well experienced and skilled pharmacist thoroughly educated the tuberculosis patient regarding the disease, duration of the treatment, importance of treatment completion and about possible adverse effects by using the pamphlet. Ultimately the pharmacist enables the patient to screen the ADR given in the pamphlet during the treatment and how to tackle them. The knowledge was evaluated after the counseling for analyzing the knowledge of the patient regarding his treatment. And re-counseling was performed if it is necessary.

\section{Results and Discussion}

The study was carried out in the pulmonology department of Kovai Medical Center and Hospital at Coimbatore, over a period of 8 months from May to December 2010. Study results were summarized in tables 1 and 2. A total of 110 patients were incorporated in the study. Of the whole population 63 (57.27\%) were inpatients and $47(42.73 \%)$ were outpatients. Among the total population, 77 (70\%) were male and $33(30 \%)$ were females. It is found that males were more prone to tuberculosis when compared to females with a ratio of 7:3. A study conducted by Mahmood et al. [5], reveals that the pervasiveness of tuberculosis is more in males than females with a ratio of 5:1. Also the National Tuberculosis Program (NTP) summarized as the ratio of the occurrence of TB between the male and female were 5:2. One of the study performed by Jaggarajamma et al. [19], has the identical outcome alike to ours in case of the gender wise occurrence of the TB, which contributes that a 7:2.5 ratio of male and female incidence of TB. Not only these studies, some other studies also point out that the TB is more prone to male gender like in our study [7-10].

The mean age of the study population was found to be $45.61 \pm 15.26$. Previous data's regarding the age group who were more prone to TB shows dissimilar conclusions. According to RNTCP status report (TB India 2006) TB affects habitually in young adults with an age range of '25-34' [26]. A review through some other studies also reveals the same [27]. A descriptive study executed by Habib-ullah et al. [9], reveals that the mean age group for TB occurrence is $42.10 \pm 20.38$. The mean age of the TB patients from the study population of Marra et al. [10], were also found to be $49.9 \pm 20.9$. Both of these two studies were supporting to the current study outcome.

Among the total population 93 (84.55\%) were married. Literacy status of entire population justified that $54(49.09 \%)$ patients have a literacy level of " $1-10$ ". Out of the study population 78 (70.91\%) patients were not having the smoking habit.

In our study about $85(77.27 \%)$ patients were diagnosed as pulmonary TB in our study population. About $92 \%$ of the populations in the research of Jaggarajamma et al. [19] were diagnosed as Pulmonary Tuberculosis (PTB). A study reported by Habib-ullah et al. [9], interpret that $73 \%$ of the study population were diagnosed as PTB which was matching to our study. Of the remaining patients in our study, 7 (06.36\%) patients were found to have TB lymphadenitis as well as TB pleuritis. TB pleural effusion and silico TB were found in 4 (03.64\%) patients. $2(01.81 \%)$ patients were diagnosed to have miliary $\mathrm{TB}$ and the remaining $1(00.91 \%)$ patient was diagnosed as spinal TB. It shows that when compared to EPTB, PTB shows most occurrences as per the prior study conclusions $[8,9,19]$.

Among the full population 43 (39.09\%) patients experienced at least one ADR during the time of study period (Figure 1). The prevalence of ADR occurrence as per three different studies [5,10,11] during the intensive phase of ATT were found to be $22 \%, 30 \%$, and $55 \%$.

Out of 43 ADR victims 29 (67.44\%) were male and 14 (32.59\%) were females. Majority of them were males and the statistically there is no significant relation between the occurrence of ADR and gender $[11,12]$. The most prone age group for ADR incidence was found to be '46-60' group comprising of 20 (46.51\%) patients followed by ' $31-45$ ' group which includes about $10(23.26 \%)$ patients. This result is controversial to the study of Chhetri et al. [11], in which the most prominent age group for the occurrence of ADR for ATT were belongs to '21-30' group. The statistical result shows that there is no significant 
Citation: Abideen PS, Chandrasekaran K, Uma Maheswaran, Vijayakumar A, Kalaiselvan V, et al. (2013) Implementation of Self Reporting Pharmacovigilance in Anti Tubercular Therapy Using Knowledge Based Approach. J Pharmacovigilance 1: 101. doi:10.4172/2329-6887. 1000101

Page 3 of 5

relationship between the age and ADR which is similar to the previous study. While evaluating the age group for major ADR in gender wise, 18 (62.07\%) male patients were belongs to the age group ' $46-60$ ', and 5 (35.71\%) female patients were in the age group of ' $31-45$ '.

A total of 74 ADRs have been experienced by these 43 patients, the pattern of ADR have been represented in the table 2. Among the 43 ADR victims 23 (53.49\%), 12 (26.91\%), 5 (11.62\%) and 3 (06.98\%) patients showed one, two, three and four different ADR's respectively (Figure 2). Out of 74 ADRs, 17 (22.97\%) were elevated liver enzymes, which is the most prominent one followed by vomiting and joint pain. Drug induced liver problem is not a rare problem in ATT. It is seen that $20 \%$ hepatotoxic ADR victims in the study of Khalid et al. [8], proved that liver, biliary system and gastro intestinal system are the most frequent organ systems effected by ADRs for anti tubercular drugs $[10,12]$. It shows that hepatitis followed by the vomiting were the major ADRs occurred in the population of the study of Marra et al. [10], which is similar to our study. The time interval between start of therapy and onset of ADR is demonstrated in figure 3. It was found that 37 (50\%) ADRs occurred within 15 days after starting the therapy. An overview of the figure 3 shows that as there is a decreased incidence of ADRs when the days get increased. This is quite similar to the study of Kheirollah et al. [12].

The categorization of the observed ADRs during the time of each review on the basis of exclusion and inclusion criteria of our study protocol was summarized in table 3. Out of 74 ADRs, 16 during the hospital stay only. Remaining 58 ADRs were occurred during the whole review period, in which 34 were excluded from the self report. 24 ADRs were included in the category, which is need to report according to the study protocol.

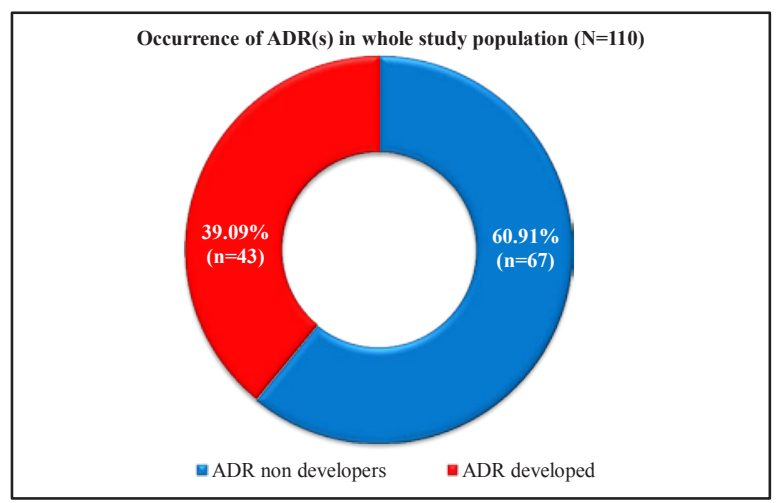

Figure 1: Occurrence of ADRs

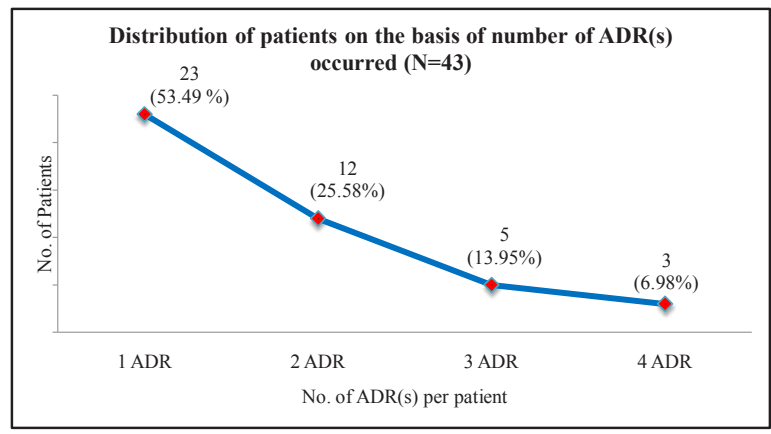

Figure 2: Number of $A D R(s)$ occurred per patient.

\begin{tabular}{|l|c|}
\multicolumn{1}{|c|}{ Parameters of all patients } & Frequency $(\%) \mathbf{N}=\mathbf{1 1 0})$ \\
\hline Gender & \\
\hline Males & $77(70 \%)$ \\
\hline Females & $33(30 \%)$ \\
\hline Age & $24(21.82 \%)$ \\
\hline $16-30$ & $27(24.55 \%)$ \\
\hline $31-45$ & $\mathbf{4 3}(39.09 \%)$ \\
\hline $46-60$ & $16(14.54 \%)$ \\
\hline $61-75$ & \\
\hline Literacy Level & $29(26.36 \%)$ \\
\hline Illiterate & $\mathbf{5 4}(\mathbf{4 9 . 0 9 \% )}$ \\
\hline $01-10$ th class & $27(24.55 \%)$ \\
\hline Above 10th & $32(29.09 \%)$ \\
\hline Smoking Habits & $\mathbf{7 8}(\mathbf{7 0 . 9 1 \% )}$ \\
\hline Smokers & \\
\hline Non smokers & $\mathbf{8 5}(\mathbf{7 7 . 2 7} \%)$ \\
\hline Types of TB & $07(06.36 \%)$ \\
\hline Pulmonary tuberculosis & $07(06.36 \%)$ \\
\hline TB lymphadenitis & $04(03.64 \%)$ \\
\hline TB pleuritis & $04(03.64 \%)$ \\
\hline TB pleural effusion & $02(01.81 \%)$ \\
\hline Silico TB & $01(00.91 \%)$ \\
\hline Miliary TB & \\
\hline Spinal TB & $43(39.09 \%)$ \\
\hline Adverse Drug Reactions & $67(60.91 \%)$ \\
\hline ADR developers & \\
\hline ADR non developers &
\end{tabular}

Table 1: Patients demographic data.

\begin{tabular}{|l|c|}
\hline \multicolumn{1}{|c|}{$\begin{array}{c}\text { Parameters of ADR experienced } \\
\text { patients }\end{array}$} & $\begin{array}{c}\text { Frequency of ADR (\%) } \\
\text { (N=43) }\end{array}$ \\
\hline Gender & $29(67.44 \%)$ \\
\hline Male & $14(32.59 \%)$ \\
\hline Female & $08(18.60 \%)$ \\
\hline Age group & $10(23.26 \%)$ \\
\hline $16-30$ & $20(46.51 \%)$ \\
\hline $31-45$ & $05(11.63 \%)$ \\
\hline $46-60$ & \\
\hline $61-75$ & $17(22.97 \%)$ \\
\hline ADR Reported & $13(17.57 \%)$ \\
\hline Elevated liver enzymes/hepatitis & $07(09.46 \%)$ \\
\hline Nausea \& vomiting & $06(08.11 \%)$ \\
\hline Joint pain & $05(06.76 \%)$ \\
\hline Skin rash/itch & $04(05.41 \%)$ \\
\hline Headache & $04(05.41 \%)$ \\
\hline Chest pain & $03(04.05 \%)$ \\
\hline Dysurea & $03(04.05 \%)$ \\
\hline Abdominal pain & $03(04.05 \%)$ \\
\hline Back/body pain & $03(04.05 \%)$ \\
\hline Anorexia & $02(02.70 \%)$ \\
\hline Tiredness & $01(01.35 \%)$ \\
\hline Diarrhea & $01(01.35 \%)$ \\
\hline Loss of weight & $01(01.35 \%)$ \\
\hline Giddiness & $01(01.35 \%)$ \\
\hline Visual problem & \\
\hline Pedal edema & \\
\hline &
\end{tabular}

Table 2: Occurrence of ADRs.

\begin{tabular}{|c|c|c|c|c|c|c|c|}
\hline Review & $\begin{array}{c}\begin{array}{c}\text { Adhered } \\
\text { patients } \\
(\%) \\
(\mathrm{N}=110)\end{array}\end{array}$ & $\begin{array}{c}\text { ADR } \\
\text { victims } \\
(\%) \\
(\mathrm{N}=43)\end{array}$ & $\begin{array}{c}\text { Number } \\
\text { of ADR's } \\
(\%) \\
(\mathrm{N}=58)\end{array}$ & $\begin{array}{c}\text { ADR's } \\
\text { excluded } \\
\text { from self } \\
\text { report } \\
(\%) \\
(\mathrm{N}=34)\end{array}$ & $\begin{array}{c}\text { ADR's } \\
\text { included } \\
\text { in self } \\
\text { report } \\
(\%) \\
(\mathrm{N}=24)\end{array}$ & $\begin{array}{c}\text { Number } \\
\text { of calls } \\
\text { received }\end{array}$ & $\begin{array}{l}\text { Number } \\
\text { of ADR's } \\
\text { reported }\end{array}$ \\
\hline $\begin{array}{c}1^{\text {st }} \\
\text { review }\end{array}$ & $\begin{array}{c}106 \\
(96.36)\end{array}$ & $\begin{array}{c}25 \\
(58.14)\end{array}$ & $\begin{array}{c}32 \\
(55.17)\end{array}$ & $\begin{array}{c}20 \\
(58.83)\end{array}$ & $\begin{array}{c}12 \\
(50.00)\end{array}$ & 09 & 11 \\
\hline $\begin{array}{l}2^{\text {nd }} \\
\text { review }\end{array}$ & $\begin{array}{c}104 \\
(94.54)\end{array}$ & $\begin{array}{c}16 \\
(37.21)\end{array}$ & $\begin{array}{c}23 \\
(39.66)\end{array}$ & $\begin{array}{c}12 \\
(35.29)\end{array}$ & $\begin{array}{c}11 \\
(45.83)\end{array}$ & 08 & 09 \\
\hline $\begin{array}{l}3^{\text {rd }} \\
\text { review }\end{array}$ & $\begin{array}{c}101 \\
(91.82)\end{array}$ & $\begin{array}{c}02 \\
(04.65)\end{array}$ & $\begin{array}{c}03 \\
(05.17)\end{array}$ & $\begin{array}{c}02 \\
(05.88)\end{array}$ & $\begin{array}{c}01 \\
(04.17)\end{array}$ & 0 & 0 \\
\hline Total & & 43 & 58 & 34 & 24 & 17 & 20 \\
\hline
\end{tabular}

Table 3: ADR occurrence in each review. 
Citation: Abideen PS, Chandrasekaran K, Uma Maheswaran, Vijayakumar A, Kalaiselvan V, et al. (2013) Implementation of Self Reporting Pharmacovigilance in Anti Tubercular Therapy Using Knowledge Based Approach. J Pharmacovigilance 1: 101. doi:10.4172/2329-6887. 1000101

Page 4 of 5

Of the total population $81(73.64 \%)$ patients came for the first review without $\mathrm{ADR}$, and $25(22.73 \%)$ patients came for review with 32 numbers of ADR and $4(03.64 \%)$ patients did not turn up for the review. Vomiting followed by skin rash and anorexia occurred mostly during the first review period which belongs to the inclusion criteria of the study evaluating protocol. Coming to the second review, $88(80 \%)$ patients came for the review without ADR while, 16 (14.55\%) patients came for review with 23 numbers of ADR. It was observed that the number of non compliant patient increased from 04 to 06 (05.45\%) from first review. Joint pain followed by skin rash occurred most of the times during the second review which belongs to the inclusion criteria of the study evaluating protocol. In third review, of the total population 99 (90\%) were came for review without ADR whereas $2(01.82 \%)$ patients came with 3 numbers of ADR. After reaching to the last review of our study the non complaints level is again increased from 06 to 09 . Only joint pain occurred during the third review period which belongs to the inclusion criteria of the study evaluating protocol (Table 3).

At the end of two months follow up of the study population, 9 (08.18\%) patients dropped out from the study. Communicating through telephones reveals that 4 of them continuing therapy in other hospital. 3 of them don't have the response. 2 were non-adhered. It was observed that $101(91.82 \%)$ patients were adhered to the treatment till the completion of the intensive phase. It is a great level of the compliance, and this adherence level is the directly related to the interventional educational program and the good communicative patient care system in our study. The incidence of ADR is descending order to the review period.

A total of 17 calls were received from 16 patients (1 patient called 2 times) by reporting 20 numbers of ADR (Table 3). Out of 24 ADRs need to report, $20(83.33 \%)$ ADRs were reported by $16(88.88 \%)$ patients and $4(16.67 \%)$ ADRs were not reported by $2(11.11 \%)$ patients (Figures 4 and 5). The result shows that a high percentage of patients were ready to report ADRs if the healthcare professionals give the knowledge regarding the same. A study conducted by Jarernsiripornkul et al. [28], concluded that patients were ready to report the symptoms which they believe to be due to a specific prescribed drug and it will help the early detection of ADR and thereby we can reduce severity of the same [22].

\section{Conclusion}

The attempt of implementation of self reporting pharmacovigilance for ATT in pulmonology department of Kovai Medical Center and Hospital was done, and which was authorized by the pulmonology associates. About $39 \%$ of patients suffered diverse types of ADRs due to

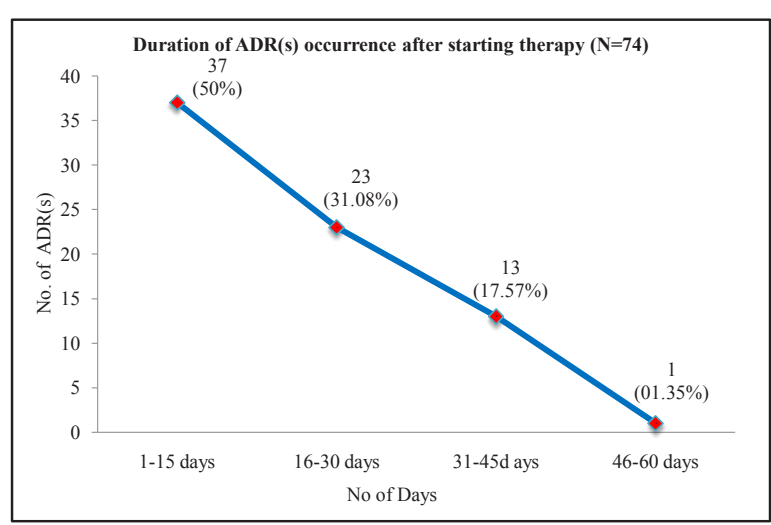

Figure 3: Relationship with occurrence of ADR and duration of therapy.

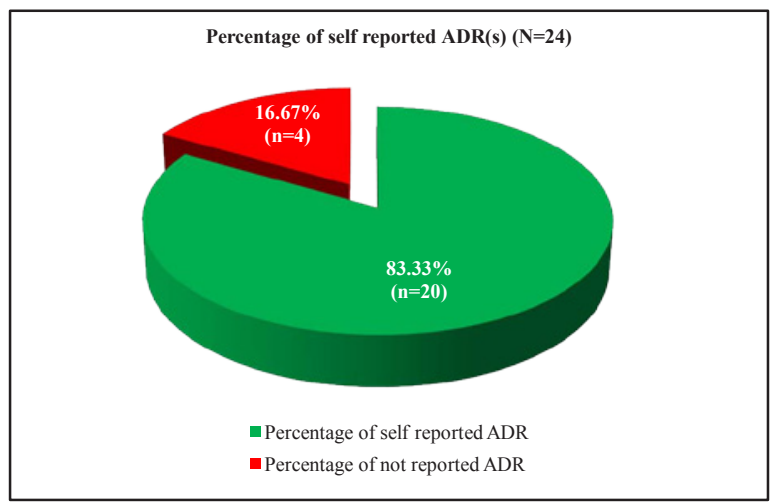

Figure 4: Percentage of self reported ADR(s).

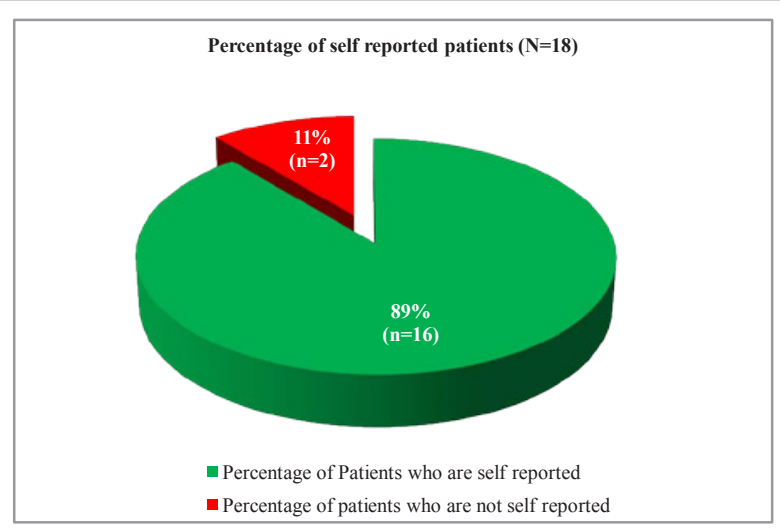

Figure 5: Percentage of self reported patients.

ATT in the pulmonology department of our hospital during the period of study. Predominantly it is a privileged percentage of ADRs, to take a decision for implementing a good patient care oriented program by the health care professionals. As a pharmacist, we have the liability to support the patients during the periods of ATT, while they were suffering these kinds of unwanted effects of the drug. These unwanted effects may steer the patient to make a judgment for stopping the medications and finally the occurrence of drug resistance in country and an amplified healthcare cost. If a proper educational system is implemented like our study, most of the patients were ready to report their ADR and thereby we can improve both the patient adherence and therapeutic outcome.

A good constitutional system of communicational approach to the patient by group effort of the pharmacist and physician with the aim of complete patient care will aid for early detection of the ADRs of any drug and can trim down the incidence and severity of the same. Since DR (Drug Resistance) is the major emerging problem during ATT, implementation of well communicated system like self reporting pharmacovigilance will help to hoist the patient's self-assurance in the treatment and reduced incidence of DR. It is suggested that the clinical pharmacists and community pharmacists should exhibit their vital role during TB therapy in TB centers, pulmonology departments and DOTS centers to guarantee a better patient therapeutic outcome.

\section{Acknowledgement}

The authors acknowledge Dr. Nalla G. Palanisamy Chairman, Managing Director, Kovai Medical Center and Hospital, Coimbatore and Dr. Thavaman D. Palanisamy Trustee Kovai Medical Center Research and Educational Trust Coimbatore for providing necessary facilities and constant encouragement. We 
Citation: Abideen PS, Chandrasekaran K, Uma Maheswaran, Vijayakumar A, Kalaiselvan V, et al. (2013) Implementation of Self Reporting Pharmacovigilance in Anti Tubercular Therapy Using Knowledge Based Approach. J Pharmacovigilance 1: 101. doi:10.4172/2329-6887. 1000101

widen our heartfelt and truthful thankfulness to Dr. V. R. Pattabhiraman, M.D. DIPNB, Consultant Respiratory Sleep Medicine, and Dr. S. Mahadevan, M.D. Consultant Respiratory medicine, for their expensive guiding principle in the exposition work. We are really courtesies and pleased to them for open handed an opportunity to work along with them. We put across our honest thanks and gratitude to the Principal, Prof. Dr. A. Rajasekaran, M.Pharm., Ph.D., KMCH College of Pharmacy, for providing us with a cooperative and artistic milieu to facilitate us to work outstandingly. We coverage our thanks to the patients and their family members involved in my study, who gave their chock-full mutual aid in all the stages of this study.

\section{References}

1. Dipiro JT, Talbert RL, Yee GC, Matzke GR, Barbara GW, et al. (2005) Tuberculosis: Pharmacotherapy A Pathophysiologic Approach. (6thedn), McGraw-hill, Medical Publishing Division, New York, USA pp. 2015, 2021 2032.

2. Khan MA, Walley JD, Witter SN, Shah SK, Javeed S (2005) Tuberculosis patient adherence to direct observation: Results of a social study in Pakistan. Health policy plan 20: 354-365.

3. Erhabor GE, Aghanwa HS, Yusuph M, Adebayo RA, Arogundade FA, et al. (2000) Factors Influencing Compliance in Patients with Tuberculosis on Directly Observed Therapy at Ile-Ife, Nigeria. East Afr Med J 77: 235-239.

4. Lee JH, Chang JH (2001) Drug resistance tuberculosis in a tertiary referra teaching hospital of Korea. Korean J Intern Med 16: 173-179.

5. Mahmood I, Khalilur R, Rahman K, Hoque C, Moazzam H, et al. (2009) The Changes in Levels of Serum Alanine Aminotransferase (ALT) During Ant Tubercular Treatment With 4FDC (Fixed Drug Combination). TAJ 22: 106-110.

6. Koda-Kimble MA, Young LY, Kradjan WA Guglielmo B (2001) Tuberculosis In: Applied Therapeutics: The Clinical Use of Drugs. (7thedn), Lippincott Williams \& Wilkins, London, UK 59.8-59.9

7. Schaberg T, Rebhan K, Lode H (1996) Risk factors for side-effects of isoniazid, rifampin and pyrazinamide in patients hospitalized for pulmonary tuberculosis. Eur Respir J 9: 2026-2030.

8. Khalid M, Akhtar H, Krishan LJ, Abu T, Badar-uddin A, et al. (2007) Hepatotoxicity with Antituberculosis Drugs: The Risk Factors. Pak J Med Sci 23: 33-38.

9. Habib-ullah K, Muhammad HK, Abdul MK, Noor-ul Iman, Humera K, et al. (2009) Anti-Tuberculosis Therapy Induced Liver Injury: Frequency, Management and Outcome. J Med Sci 17: 99-102.

10. Marra F, Marra CA, Bruchet N, Richardson K, Moadebi S, et al. (2007) Adverse drug reactions associated with first-line anti tuberculosis drug regimens. Int $\mathrm{J}$ Tuberc Lung Dis 11: 868-875.

11. Chhetri AK, Saha A, Verma SC, Palaian S, Mishra P, et al. (2008) A study of adverse drug reactions caused by first line anti-tubercular drugs used in Directly Observed Treatment, Short course (DOTS) therapy in western Nepal, Pokhara. J Pak Med Assoc 58: 531-536.

12. Kheirollah G, Elahe K, Mahboubeh H, Gloria S (2006) Evaluation of antituberculosis induced adverse reactions in hospitalized patients. Pharmacy Practice 4: 134-138.
13. Begum LN, Mosharrof H, Monirul IM, Dipti RS (2006) A comparative study on the adverse effects of two anti-tuberculosis drugs regimen in initial two-month treatment period. Bangladesh J Pharmacol 1: 51-57.

14. Yee D, Valiquette C, Pelletier M, Parisien I, Rocher I, et al. (2003) Incidence of serious side effects from first-line anti tuberculosis drugs among patients treated for active tuberculosis. Am J Respir Crit Care Med 167: 1472-1477.

15. Johnson J, Kagal A, Bharadwaj R (2003) Factors associated with drug resistance in pulmonary tuberculosis. Indian J Chest Dis Allied Sci 45: 105-109.

16. Kochi A (1991) The global tuberculosis situation and the new control strategy of the World Health Organization. Tubercle 72: 1-6.

17. Munro SA, Lewin SA, Smith HJ, Engel ME, Fretheim A, et al. (2007) Patient Adherence to Tuberculosis Treatment: A Systematic Review of Qualitative Research. PLoS Med 4: 1230-1245.

18. Alagiriswami B, Ramesh M, Parthasarathi G, Basavanagowdappa H (2009) A study of clinical pharmacist initiated changes in drug therapy in a teaching hospital. Indian J Pharm Pract 1: 36-45.

19. Jaggarajamma K, Sudha G, Chandrasekaran V, Nirupa C, Thomas A, et al (2007) Reasons for non-compliance among patients treated under Revised National Tuberculosis Control Programme (RNTCP), Tiruvallur district, south India. Indian J Tuberc 54: 130-135.

20. Xu W, Lu W, Zhou Y, Zhu L, Shen H, et al. (2009) Adherence to anti-tuberculosis treatment among pulmonary tuberculosis patients: a qualitative and quantitative study. BMC Health Serv Res 9: 169.

21. Raja RCP, Ramesh A (2009) Design and Implementation of Adverse Drug Reaction Reporting System in Community Pharmacies. Indian J Pharm Pract 2: 31-37.

22. Jarernsiripornkul N, Chaisrisawadsuk S, Chaiyakum A, Krska J (2009) Patient self-reporting of potential adverse drug reactions to non-steroidal antiinflammatory drugs in Thailand. Pharm world Sci 31: 559-564.

23. Campbell JP, Howie JG (1988) Involving the patient in reporting adverse drug reactions. J R Coll Gen Pract 38: 370-371.

24. Mitchell AS, Henry DA, Fisher RS, O'Connell DL (1988) Patients as a direct source of information on adverse drug reactions. BMJ 297: 891-893.

25. Krska J, Jarernsiripornkul N, Capps PAG, Richards RME (2001) Patients self reports of potential adverse drug reactions. Int J Pharm Pract R35.

26. Government of India (2006) TB India 2006, RNTCP Status Report, DOTS for All-All for DOTS, Ministry of Health and Family Welfare, New Delhi.

27. Bello SI, Itiola OA (2010) Drug adherence amongst tuberculosis patients in the University of Ilorin Teaching Hospital, Ilorin, Nigeria. Afr J Pharm Pharmacol 4: 109-114.

28. Jarernsiripornkul N, Krska J, Capps PA, Richards RM, Lee A (2002) Patient reporting of potential adverse drug reactions: a methodological study. $\mathrm{Br} \mathrm{J}$ Clin Pharmacol 53: 318-325. 